\title{
Wing tags severely impair movement in African Cape Vultures
}

\author{
Teja Curk ${ }^{1,2^{*}+}$, Martina Scacco ${ }^{1,2+}$, Kamran Safi ${ }^{1,2}$, Martin Wikelski ${ }^{1,2,3}$, Wolfgang Fiedler ${ }^{1,2}$, Ryno Kemp $^{4}$ \\ and Kerri Wolter ${ }^{4}$
}

\begin{abstract}
Background: The use of tracking technologies is key for the study of animal movement and pivotal to ecological and conservation research. However, the potential effects of devices attached to animals are sometimes neglected. The impact of tagging not only rises welfare concerns, but can also bias the data collected, causing misinterpretation of the observed behaviour which invalidates the comparability of information across individuals and populations. Patagial (wing) tags have been extensively used as a marking method for visual resightings in endangered vulture species, but their effect on the aerodynamics of the birds and their flight behaviour is yet to be investigated. Using GPS backpack mounted devices, we compared the flight performance of 27 captive and wild Cape Vultures (Gyps coprotheres), marked with either patagial tags or coloured leg bands.

Results: Individuals equipped with patagial tags were less likely to fly, travelled shorter distances and flew slower compared to individuals equipped with leg bands. These effects were also observed in one individual that recovered its flight performance after replacing its patagial tag by a leg band.

Conclusions: Although we did not measure the effects of patagial tags on body condition or survival, our study strongly suggests that they have severe adverse effects on vultures' flight behaviour and emphasises the importance of investigating the effects that tagging methods can have on the behaviour and conservation of the study species, as well as on the quality of the scientific results.
\end{abstract}

Keywords: Tag attachment, Bio-logging, Flight performance, marking, Patagial tag, Leg band, Vultures

\section{Background}

When measuring a phenomenon, the mere process of recording it influences our comprehension of the phenomenon itself [1]. The rapid development of tracking technologies and miniaturised sensors (bio-logging) allows us to finally answer long standing hypotheses about animal behaviour while providing a fertile environment to tackle novel research questions [2]. GPS loggers and geolocators record animal movements,

\footnotetext{
*Correspondence: tcurk@ab.mpg.de

${ }^{\dagger}$ Teja Curk and Martina Scacco contributed equally to this work and are co-first authors

${ }^{1}$ Department of Migration, Max Planck Institute of Animal Behavior, Am Obstberg 1, 78315 Radolfzell, Germany

Full list of author information is available at the end of the article
}

accelerometers, cameras and proximity sensors can inform us about detailed behaviours and interactions among individuals and internal sensors such as heart rate loggers can provide information about the animals' physiology. Finally, additional sensors can report on the environmental conditions experienced by the animals, such as temperature, air or water pressure and water depth.

The detail and spatial coverage of these data and the fact that they can be collected remotely from wild freeranging animals are unprecedented, and impossible to achieve using direct observation [3]. Therefore the use of bio-logging and especially tracking technology is fundamental for the study of animal movement and pivotal to ecological and conservation research. However, the

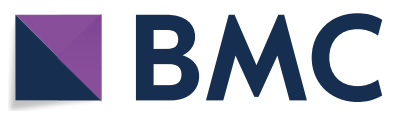

(C) The Author(s) 2021. This article is licensed under a Creative Commons Attribution 4.0 International License, which permits use, sharing, adaptation, distribution and reproduction in any medium or format, as long as you give appropriate credit to the original author(s) and the source, provide a link to the Creative Commons licence, and indicate if changes were made. The images or other third party material in this article are included in the article's Creative Commons licence, unless indicated otherwise in a credit line to the material. If material is not included in the article's Creative Commons licence and your intended use is not permitted by statutory regulation or exceeds the permitted use, you will need to obtain permission directly from the copyright holder. To view a copy of this licence, visit http://creativeco mmons.org/licenses/by/4.0/. The Creative Commons Public Domain Dedication waiver (http://creativecommons.org/publicdomain/ zero/1.0/) applies to the data made available in this article, unless otherwise stated in a credit line to the data. 
potential bias caused by the process of data collection has been often underrated.

Researchers are aware that tagging devices might affect the behaviour and survival of animals and more and more studies are suggesting solutions to minimise their effects, despite these being difficult to estimate and account for when interpreting results. Several studies have shown that the behaviour of birds can be affected by the attached devices [4-6]. A study on migrating birds, highlighted how return rates of individuals carrying geolocators were significantly lower than in the control group [7]. Devices attached to birds were also shown to negatively influence reproduction, nesting, parental care and survival, to reduce flight speeds $[8,9]$, and to increase energy expenditure $[4,6]$. Some studies demonstrated an extension of the foraging trip duration due to the attached devices [6] whereas Wanless et al. [10] reported shorter foraging trips for birds equipped with devices compared to the control group.

These behavioural changes can not only have a negative impact on the reproduction and survival of animals [6], but also bias our understanding of animal behaviour [4]. In fact, effects of tagging methods pose, beyond being a concern for animal welfare, a major problem because of their systematic bias on the data. So far, there has been little or no research on how tagging methods affect the movement metrics that we collect and analyse, and on which we base our understanding of the behaviour in a population. Although, the effects of devices on animals are difficult to measure, we need to increase our efforts towards quantifying and understanding them. By underestimating the effects of devices we risk to invalidate the efforts of our research community in studying and preserving animal behaviour, especially in the case of threatened species which are often subjects of movement ecology studies.

The weight of a device, relative to an animal's body weight (a currently accepted upper limit of to date $3 \%$ or $5 \%$ ), is in general the only aspect currently considered in movement ecology studies involving tracking technology or marking methods $[11,12]$. Yet, also other aspects, such as device attachment (where and how the device is attached to the animals body) and device-induced drag, have been shown to affect flight behaviour [13]. In order to avoid these negative effects, researchers recommended to minimise the weight and reduce the drag coefficient of the device $[5,9,14,15]$, to use flexible harnesses to reduce injuries for the birds $[4,16]$, and to position the devices at the centre of gravity to avoid destabilisation $[1$, 10, 17].

Patagial tags have been extensively used as markers in the last decades and have played an important role in behavioural studies. However, several studies confirmed adverse effects of patagial tags related to behaviour, nesting success and survival [18-20]. Studies on vultures, suggested that patagial tags might affect the aerodynamics of flight by impacting lift [21], which could negatively affect the energetic cost of flight. The severity of these effects also depends on tag material, as plastic tags might lift off the surface of the wing during flight and have a stronger impact compared to softer vinyl tags, which lie flat on the wing [22]. If the weight and drag of a tag on the wing were problematic per se, the way in which anatomic structures of the wing interact during flight makes the exact placement of such a tag even more so. A recent review on proper patagial tag placement highlighted how an incorrect placement of a tag on the patagium can cause injuries and result in the grounding of vultures [23]. Most of the vulture populations currently studied are endangered and in dire need of informed conservation action; hence studying their movements while finding the least invasive tagging technique to study their behaviour has become a priority. Researchers recently introduced leg bands as an alternative to patagial tags for individual identification [23]. In addition to marking methods, researchers use GPS tracking devices to follow individual trajectories and asses habitat use, resource selection and flight performance.

In this study, we compare the impact of patagial tags $v s$ leg bands on the flight performance of an endangered soaring bird species, the Cape Vulture (Gyps coprotheres). Specifically, we investigate the effects of tag attachment in wild and captive bred individuals on flight probability, proportion of time spent flying, cumulative distance travelled and ground speed.

\section{Results}

Between 2015 and 2019, we used GPS devices to track 27 vultures (14 wild and 13 captive bred) and marked them with either patagial tags ( 15 birds) or leg bands (13 birds). The trajectories of the 27 individuals covered an area between $-17^{\circ}$ and $-32^{\circ}$ latitude. Individuals equipped with different tag attachments showed clear differences in the area they covered during the tracking period (Fig. 1). The final data set consisted of 5822 tracking days between April 2015 and November 2019, of which 2292 corresponded to birds equipped with leg bands (1079 of wild and 1213 of captive individuals), and 3530 to birds wearing patagial tags (1870 of wild and 1660 of captive individuals). The average tracking time for the individuals in the study was $2380.1 \pm 302.7 \mathrm{~h}$ [mean $\pm \mathrm{SE}$; min $=$ $172.5 \mathrm{~h}, \max =7027.6 \mathrm{~h}$ ]. The number of segments per day considered in the analysis ranged from 1 to 82 and among all individuals, we recorded 2974 days (51\%) in which no flight segment was recorded. 


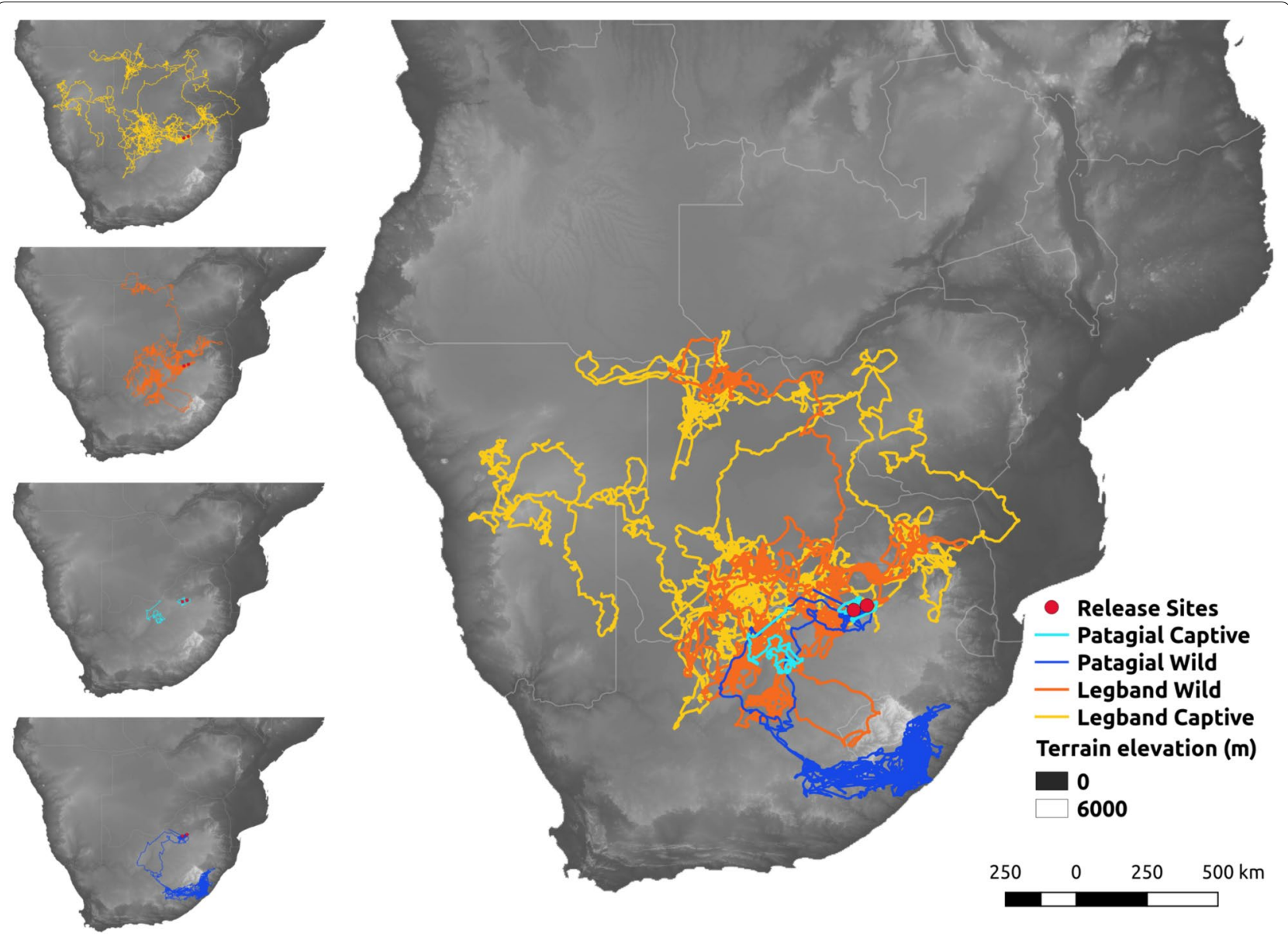

Fig. 1 GPS trajectories of 27 African Cape Vultures, wild and captive, equipped with either leg bands or patagial tags. Colours show the four combinations of these categories. Red points indicate the release sites

In days when at least one flight segment was recorded, the birds flew only $11.3 \pm 0.002 \%$ [mean \pm SE] of their daily tracking time, and covered a daily distance of 70.8 $\pm 1.2 \mathrm{~km}$ flying on average with a daily median ground speed of $6.9 \pm 0.05 \mathrm{~ms}^{-1}$. A comparison of the raw data between attachment types and groups showed that the proportion of days with flight and the daily values of proportion of time spent flying, cumulative distance travelled and median ground speed were the lowest in captive birds equipped with patagial tags and the highest in birds wearing leg bands (similarly so between captive and wild; Fig. 2).

During the study, one captive vulture originally released with a patagial tag was found grounded, whereupon its patagial tag was replaced with a leg band (see Methods). After the tag replacement, we detected an increase in the flight parameters (Fig. 3) for this individual.

Inferences about the effect of tag attachment and group on the flight performance of the birds were drawn based on the results of four generalized additive mixed models
(GAMMs). Flight probability, proportion of time spent flying, daily cumulative distance travelled and ground speed were included as response variables. In all four models, attachment type and group (captive or wild) and their interaction term were included as predictors. To account for the uneven tracking effort we additionally included the number of daily locations and number of days since release.

\section{Occurrence of flight (flight probability)}

Occurrence of flight (0-absence, 1-presence) was included as a response variable in the first GAMM. This model contained 5822 observations (days) of which 2292 belonged to the leg band group $(0=656,1=1636)$ and 3530 to the patagial group $(0=2318,1=1212)$, for a total of 27 individuals. The proportion of days in which no flight was recorded was higher for individuals wearing patagial tags $(65.6 \%)$ compared to those wearing leg bands (28.6 \%; Fig. 2). Our model predicted flight probability to be lower (albeit not significantly) for wild 

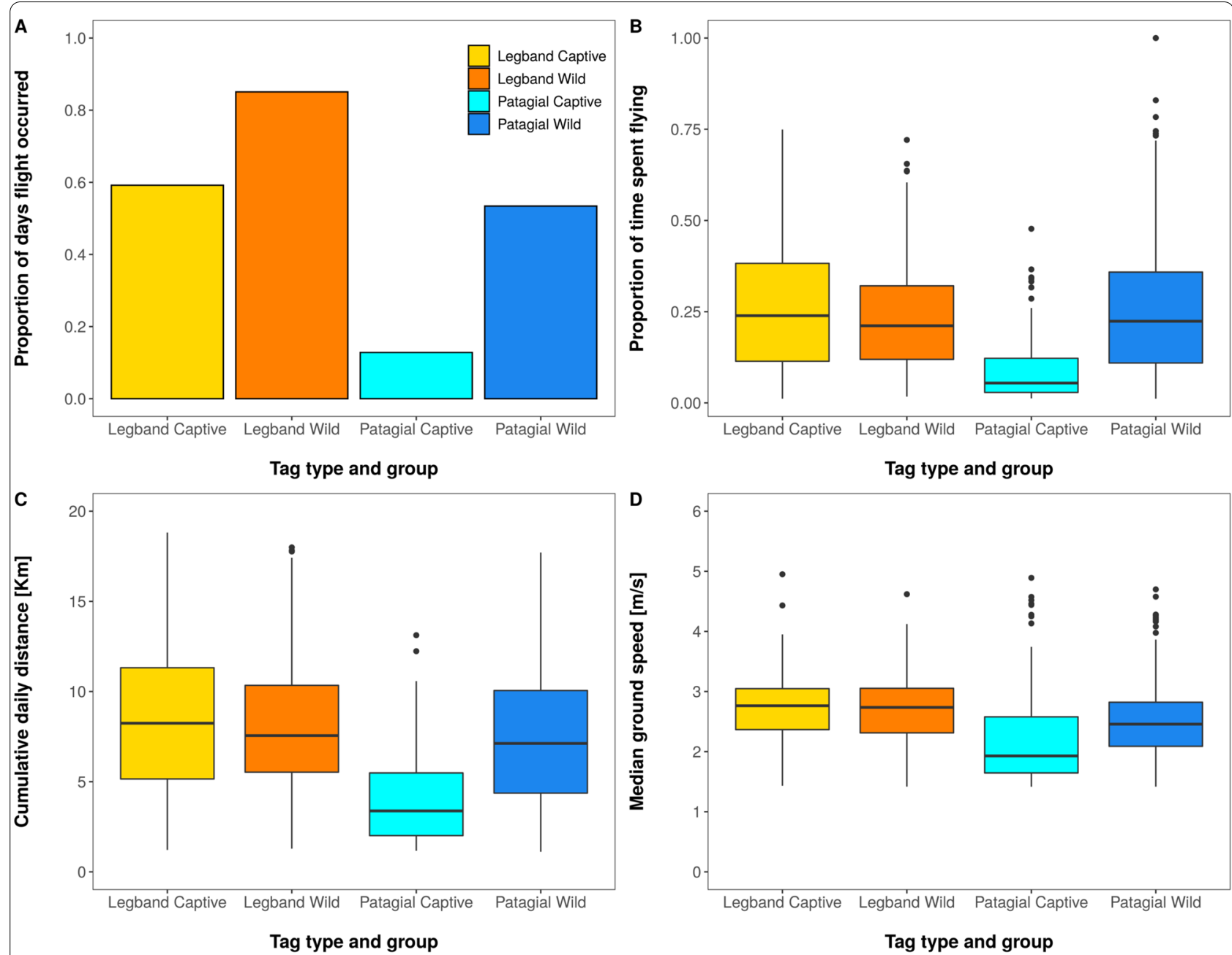

Fig. 2 a Proportion of tracking days in which flight occurred, $\mathbf{b}$ daily proportion of time spent flying, $\mathbf{c}$ daily cumulative distance travelled, and $\mathbf{d}$ daily median ground speed, across groups. Different colours differentiate the four groups: captive bred individuals equipped with leg bands, wild individuals equipped with leg bands, captive individuals equipped with patagial tags and wild individuals equipped with patagial tags

individuals equipped with patagial tags compared to wild individuals equipped with leg bands (patagial $=-1.47$ \pm 0.79 [estimate $\pm \mathrm{SE}]$ ). The effect of patagial tags on flight probability was the strongest and lower than the significance threshold $(p<0.05)$ for captive individuals equipped with patagial tags (patagial:captive $=-2.20$ \pm 0.83 ). We detected no significant difference between captive and wild individuals equipped with leg bands. Indeed, our model predicted the highest probability to fly $(84 \%)$ for wild individuals with leg bands and the lowest $(6.47 \%)$ for captive individuals with patagial tags. Among-individual variability was quite high, with $95 \%$ of the individuals having a flight probability between $24.5 \%$ and $98.8 \%$. However, the variability attributable to individual variation (intercept $\mathrm{SD}=1.42$ ) was lower than the effect associated with the patagial attachment both on wild and captive individuals (Table 1 ).
All smooth terms included in the model (duration, i.e. number of days since deployment, number of locations and Julian date) had a significant effect on the occurrence of flight. Flight probability increased with the number of locations until around 50 locations, indicating that using a number of daily segments $<50$ could result in a lower probability of detecting flight. Flight probability was highest (>50\%) between the end of May and the beginning of September (days 150-250). The tracking duration (number of days since deployment) positively influenced flight probability after 500 days (about 1.4 years) from deployment (see Additional file 1: Fig. S1).

The following three models were all run only on days in which at least one flight segment was recorded $(n=$ 2848 days, 1636 corresponding to leg band and 1212 to the patagial group for 27 individuals). 


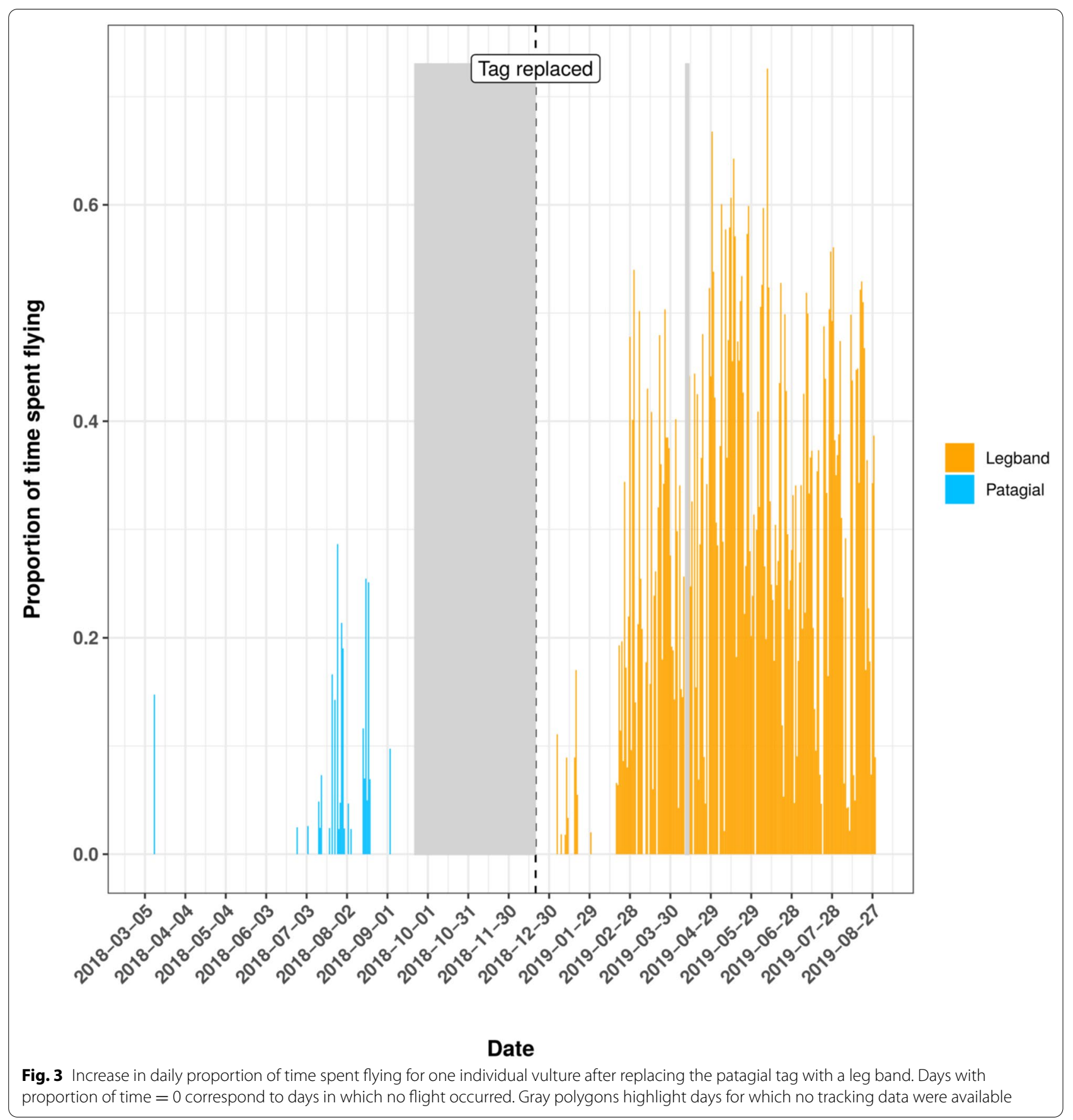

\section{Daily proportion of time spent flying}

Daily proportion of time spent flying did not differ significantly for individuals wearing patagial tags, compared to leg bands, nor did it differ between captive and wild individuals. The difference between the groups spending the highest and the lowest proportion of their time flying was rather small: 0.20 for wild individuals wearing patagial tags (patagial $=0.11 \pm 0.14$ ) and 0.16 for captive individuals with patagial tags (patagial:captive $=-0.17 \pm$ 0.14 ). $95 \%$ of the individuals showed a proportion ranging from 0.11 to 0.27 , making among-individuals variability high (intercept $\mathrm{SD}=0.26$ ) compared to the effect of tag attachment and group (Table 2).

Tracking duration, number of daily locations and Julian date, all included as smooth terms in the model, had a statistically significant effect on the proportion of time 
Table 1 GAMM with occurrence of flight included as dependent variable, interaction between tag attachment and group as fixed term and individual identity as random intercept

\begin{tabular}{|c|c|c|c|c|}
\hline Coefficients & Estimates & SE & $t$ & $p$ \\
\hline Intercept & 1.66 & 0.59 & 2.79 & $* *$ \\
\hline Patagial attachment & -1.47 & 0.79 & -1.86 & NS \\
\hline Captive group & -0.66 & 0.73 & -0.92 & NS \\
\hline Patagial:Captive & -2.20 & 0.83 & -2.65 & $* *$ \\
\hline Smooth terms & Edf & Ref. df & $F$ & $p$ \\
\hline Tracking duration & 5.93 & 5.93 & 6.62 & $* * *$ \\
\hline N. Locations & 5.88 & 5.88 & 23.35 & $* * *$ \\
\hline Date & 6.75 & 8.00 & 13.99 & $* * *$ \\
\hline Random effects & & Intercept Std. Dev & & N. Groups \\
\hline Individuals & & 1.42 & & 27 \\
\hline Random effects & & Intercept Std. Dev & & N. Groups \\
\hline N. Observations & & 5822 & & \\
\hline Adjusted $R$ & & 0.30 & & \\
\hline
\end{tabular}

Number of days since deployment, number of locations and day of the year were included as smooth terms. The model was fitted with the restricted maximum likelihood using the binomial family and a logit link function

NS $p \geq 0.05 ;{ }^{*} p<0.05 ;{ }^{* *} p<0.01 ;{ }^{* * *} p<0.001$

spent flying. Proportion of time spent flying increased with the number of daily locations and reached its maximum at around 30 locations, indicating that recording < 30 segments per day would decrease our chances to identify flight segments. The model showed a small seasonal effect on the proportion of time spent flying, with a small increase between the beginning of April and the end of October. The proportion of time spent flying did not to be influenced by the duration of the tracking period (see Additional file 1: Fig. S2).

\section{Daily distance travelled}

Wild individuals equipped with patagial tags travelled significantly shorter distances, of about $10 \mathrm{~km}$ less, compared to wild individuals equipped with leg bands (effect size patagial $=-0.65 \pm 0.22$ ). In captive bred individuals, the difference between distance travelled when wearing leg bands and patagial tags was smaller than in wild individuals (about $7 \mathrm{~km}$ ) and statistically non-significant. When comparing within the same tag attachment type, we did not find any significant difference between wild and captive bred individuals. The random structure of the model showed small among-individual variation, with 95 $\%$ of the individuals travelling between 50 and $72 \mathrm{~km} /$ day. The variability attributable to individual variation (intercept $\mathrm{SD}=0.37$ ) was lower relative to the effect associated to the patagial attachment on wild birds (Table 3).

The positive and significant effect of the number of daily locations suggests that collecting a higher number of segments per day would result in recording larger daily distances. Our model showed no seasonal effect on the distance travelled and no increase or decrease in daily movement with the number of days from release (see Additional file 1: Fig.S3).

\section{Daily median ground speed}

Wild individuals equipped with patagial tags reached significantly lower ground speeds (about $0.88 \mathrm{~ms}^{-1}$ less) compared to wild individuals wearing leg bands (effect size patagial $=-0.17 \pm 0.07$ ). The model showed no significant differences between wild and captive bred individuals, however the effect sizes suggest that captive individuals wearing leg bands travelled at the fastest speeds, about $7.2 \mathrm{~ms}^{-1}$, while captive individuals with patagial tags at the lowest, about $5.9 \mathrm{~ms}^{-1}$ (patagial:captive $=-0.09 \pm 0.09$ ). Among-individuals variability was relatively high (intercept $S D=0.10$ ) if compared to the largest effect size due to the patagial attachment, and $95 \%$ of the individuals showed a daily median speed between 6 and $8 \mathrm{~ms}^{-1}$ (Table 4).

The number of daily locations, duration of tracking and Julian date significantly influenced median ground speed. Daily median ground speed significantly increased with the number of daily locations and reached an asymptote at around 25 locations. Ground speed also increased until around 200 days (about seven months) after deployment but this increase was not consistent over time. The model 
also showed a seasonal effect on the daily ground speed, with a slight decrease in speed between the beginning of April and the end of October (see Additional file 1: Fig. S4).

\section{Discussion}

We have demonstrated that tag attachment has a severe impact on the flight performance of Cape Vultures. Individuals equipped with patagial tags covered a much smaller area compared to the leg band group. Our results showed that both wild and captive individuals equipped with patagial tags were significantly less likely to take flight (lower proportion of days in which flight occurred) and when doing so flew at significantly lower ground speed compared to individuals wearing leg bands. Although statistically not significant, we believe it to be relevant that among all groups, captive individuals wearing patagial tags also spent the least proportion of time flying. Finally and as a consequence of the above, our models also showed that wild birds equipped with patagial tags travelled significantly shorter distances compared to those wearing leg bands.

The four groups showed different general directions of movement: individuals in the patagial wild group either remained in the release area or moved towards SE and patagial captive individuals mainly remained in the release area or moved SSW, while both leg band groups showed a movement pattern towards NNW. While the smaller area covered by the patagial groups is in line with our results, there is no obvious hypothesis behind the differences in movement direction observed between groups. However, we could speculate that an interplay of different environmental conditions, including resource distribution and weather conditions, could be the cause of such pattern. Different groups could be attracted to different sources of food, and specific local weather conditions, such as main wind directions at different times and locations, could be guiding the birds to different areas.

Age and experience are known to affect ranging behaviour and distance travelled in vultures, with younger individuals moving more than older ones, who already established their breeding territories [24, 25]. In this study, due to our small sample size, it was not possible to account for age in the models. Our dataset included 21 individuals among which were fledglings, juveniles and subadults and only six adults. However, the adult individuals were equally distributed between the two attachment types, thus we are confident that omitting age from the models did not bias our findings.

Shorter daily distance travelled means smaller area covered every day by the birds to forage. Vultures are scavengers and as such cover large areas to feed on ephemeral food resources [26]. At individual and population level, a restricted flight potential and therefore a restricted area available to forage might not be a problem if food resources are abundant, but they surely reduce an individual's ability to react to changes in food availability and environmental conditions. A restricted area covered daily by these birds can also lead to ecosystem-level effects. Scavengers play an important role in the ecosystem thanks to the services they provide, such as preventing the spread of infectious diseases, recycling organic material into nutrients and stabilising food webs [27]. Therefore a restricted flight potential and reduction in the area covered by these birds caused by improper tag attachment can have far-reaching consequences at the ecosystem level.

Our results are consistent with previous studies, showing that tag attachment influences foraging trip duration. In some studies, birds carrying extra weight had shorter foraging trips $[10,17]$. Other studies investigating the effect of device weight, however, showed that birds carrying devices exhibited longer foraging trips $[6,28,29]$, suggesting that individuals wearing extra weight might have to compensate for their increased greater energy demands by travelling more and farther in search for food [13, 17, 30, 31]. This might raise questions about whether the decrease in the four flight parameters included in our study should be considered detrimental for the birds. Unfortunately, we did not have access to information about body condition, fitness or survival rate of the individuals after they were tagged. Hirschauer et al. [23] found that patagial tags can be easily misplaced, and that birds equipped with improperly attached patagial tags were more often found grounded or injured. The results of our study increase the understanding of the effects of patagial tags. By comparing patagial tags and leg bands we suggest that patagial tags, even when properly attached, decrease the birds' flight performance, likely increasing the probability of grounding.

All birds included in the study were equipped with a GPS in addition to the marking method (patagial or leg band), which might raise concerns in terms of potential cumulative effect of the two devices. Flight parameters from control birds without GPS devices would be difficult to measure and could only be obtained using direct observations. We can therefore only speculate about the cumulative effect of GPS and patagial tags on the flight performance. However, all birds were equipped with the same type of GPS device and therefore experienced the same additional weight, the only difference being the marking method. This allowed us to estimate the effect of patagial tags on flight performance.

Previous studies suggested that in vultures, a device attached on the wing can influence the aerodynamics of 
flight [21, 22], while to our knowledge no negative effects on flight performance have been reported for devices attached to the leg. We also presume that patagial tags affect different flight behaviours i.e. soaring, gliding and flapping differently, affecting in particular the gliding phase most severely. Patagial tags may induce a loss of lift by increasing drag. This loss of lift should thus force the birds to increase their air speed to remain aloft, which during gliding they can only achieve by increasing their sinking rate [31]. Dropping faster will consequently reduce the horizontal distances they can cover while gliding, and eventually result in lower horizontal ground speed, which is what we found in individuals equipped with patagial tags. Smaller distances covered during gliding also result in reduced chances to reach the next available uplift (soaring opportunity) or in the animals misjudging their ability to glide between thermals and thus ground them.

Our suggestion of an adverse effect of patagial tags is further supported by the anecdotal evidence of one individual vulture sequentially equipped with both types of attachment. This captive vulture, originally equipped with a patagial tag and released, was found grounded about 6 months later and after rehabilitation its tag was replaced with a leg band. The data showed that after the tag replacement, all flight parameters measured for this individual increased to match the movement parameters of the other leg banded individuals, suggesting that this individual was rather hampered previously in its movement.

More research is needed to fully understand the consequences of different tagging methods on vultures, including their direct effects on body condition, reproduction and survival. Nonetheless, we urgently recommend using leg bands instead of patagial tags. Should the use of patagial tags be considered unavoidable, we urge researchers to consult experts about the exact positioning of the tag on the patagium (see the manual in [23]). Some researchers in South Africa already started replacing patagial tagging with leg banding. Fast implementation of such changes, in response to up cutting-edge research on the topic, are especially important for endangered and critically endangered species, such as the Cape Vulture and other African vulture species which are declining in numbers dramatically [32]. In such species, the use of the least invasive tagging method can have a significant impact on their population stability and extinction risk.

Tracking devices and tagging methods are under constant development and the body of literature assessing their impact is inevitably not comprehensive. The challenging task for the movement ecology research community is to keep up with the methodological developments by studying how different devices and attachments affect animal behaviour in order to improve current methods to minimise their impact [16]. In addition to reducing the weight of the devices attached on animals, researchers should empirically examine the negative effects of the attached devices, device size and deployement duration on the study species [12] and take advantage of the simulation approaches to optimize tag design and reduce drag [15]. Equipping birds with devices generally affects many aspects of their behaviour and ecology [4]. In several cases, however, studies reported contradicting results of the effects of different devices on birds $[4,33]$. For example, some studies showed adverse effects of patagial tags while others reported no effects [33]. The reason for that could be that different species respond differently to the attachment of devices because of their ecological differences [6]. When assessing which device to use, it is therefore necessary to understand its impacts on the specific study species or on phylogenetically related or functionally similar species. Discrepancies between studies may also be generated by differences in the temporal and special scales at which data were collected, or by differences in the environmental conditions the animals experienced [6]. Therefore, to gain a better understanding of the impact of tagging methods, it is important to take into account possible differences due to methodology (e.g. tag type, sampling schedule), environmental context (e.g. seasonality), and different aspects of the species' biology (i.e. flight, body condition, reproduction) $[4,6]$.

\section{Conclusions}

Researchers need to balance the benefits of data acquired by tracking animals with the adverse consequences on the animals' health and the potential biases on the scientific results. These biases invalidate the comparability of information across individuals and populations tagged with different methods, and defeat the purpose of generalising our behavioural conclusions beyond the single device and attachment. As movement ecologists we aim to study the movement behaviour of animals in different conditions to predict how different species or population would react to changes in their environment. Comparisons at different spatial and temporal scales are therefore an important part of our field of research, but these comparisons risk to become meaningless if we choose to ignore the biases due to how we measure the phenomenon we observe.

\section{Methods}

\section{Data collection}

Between 2015 and 2019, we tracked 27 Cape Vultures in South Africa (14 males and 13 females of which six were adults, four fledglings, 16 juveniles and one was a subadult). Thirteen vultures were captive bred 
and 14 wild. We equipped individuals with backpack mounted GPS devices, which were held in place between the shoulders on the birds back using harness straps that go through the inside of the birds legs and each collar bone, as described in detail by Wolter and her colleagues [34] (accessible on: https://vulpro.com/ wp-content/uploads/2020/02/Wolter-et-al-Protocolsfor-Mass-Capture-Handling-and-Fitting-tracking-devic es-on-Gyps-vultures-V3.0-Nov-20181.pdf). These birds were marked with either patagial tags (56g, Fig. 4a; 15

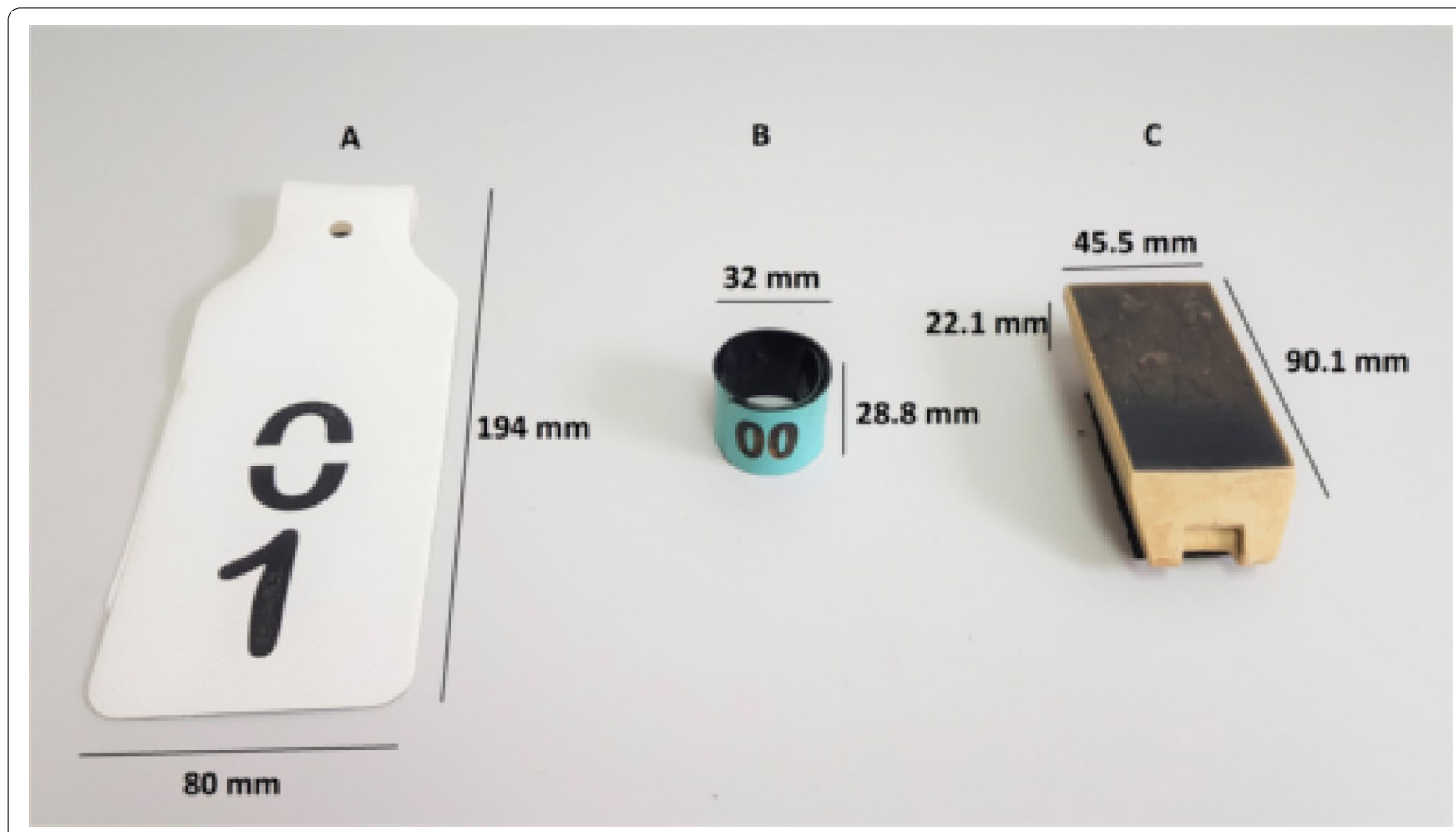

Fig. 4 Dimensions of (a) patagial tag, (b) leg band and (c) GPS device

Table 2 GAMM with daily proportion of time spent flying included as dependent variable, interaction between tag attachment and group as fixed term and individual identity as random intercept

\begin{tabular}{|c|c|c|c|c|}
\hline Coeff & Est & SE & $t$ & $p$ \\
\hline Intercept & -1.51 & 0.11 & -14.23 & $* * *$ \\
\hline Patagial att & 0.11 & 0.14 & 0.77 & NS \\
\hline Captive group & -0.09 & 0.13 & -0.69 & NS \\
\hline Patagial:Captive & -0.17 & 0.14 & -1.20 & NS \\
\hline Smooth terms & Edf & Ref. df & $F$ & $p$ \\
\hline Tracking duration & 7.28 & 7.28 & 26.03 & $* * *$ \\
\hline N. Loc & 8.92 & 8.92 & $16,584.51$ & $* * *$ \\
\hline Date & 7.68 & 8.00 & 210.37 & $* * *$ \\
\hline Random effects & & Intercept Std. Dev. & & N. Groups \\
\hline Individuals & & 0.26 & & 27 \\
\hline N. Observations & & 2848 & & \\
\hline Adjusted $R$ & & 0.93 & & \\
\hline
\end{tabular}

Number of days since deployment, number of locations and day of the year were included as smooth terms. The model was fitted with the restricted maximum likelihood using the binomial family and a logit link function

NS $p \geq 0.05 ;{ }^{*} p<0.05 ; * * 0<0.01 ; * * 0<0.001$ 
Table 3 GAMM with the square root of the daily cumulative distance included as dependent variable, interaction between tag attachment and group as fixed term and individual identity as random intercept

\begin{tabular}{|c|c|c|c|c|}
\hline Coeff & Est & SE & $t$ & $p$ \\
\hline Intercept & 7.79 & 0.16 & 49.42 & $* * *$ \\
\hline Patagial att & -0.65 & 0.22 & -2.97 & $* *$ \\
\hline Captive group & -0.09 & 0.21 & -0.44 & NS \\
\hline Patagial:Captive & 0.19 & 0.27 & 0.70 & NS \\
\hline Smooth terms & Edf & Ref. df & $F$ & $p$ \\
\hline Tracking duration & 5.34 & 5.34 & 6.37 & $* * *$ \\
\hline N. LoC & 7.28 & 7.28 & 3568.63 & $* * *$ \\
\hline Date & 5.45 & 8.00 & 3.76 & $* * *$ \\
\hline Random effects & & Intercept Std. Dev & & N. Groups \\
\hline Individuals & & 0.37 & & 27 \\
\hline N. Observations & & 2848 & & \\
\hline Adjusted $R$ & & 0.92 & & \\
\hline
\end{tabular}

Number of days since deployment, number of locations and day of the year were included as smooth terms. The model was fitted with the restricted maximum likelihood using the gaussian family

NS $p \geq 0.05 ;{ }^{*} p<0.05 ;{ }^{* *} p<0.01 ; * * * 0.001$

Table 4 GAMM with the square root of the daily median ground speed included as dependent variable, interaction between tag attachment and group as fixed term and individual identity as random intercept

\begin{tabular}{|c|c|c|c|c|}
\hline Coeff & Est & SE & $t$ & $p$ \\
\hline Intercept & 2.67 & 0.05 & 58.34 & $* * *$ \\
\hline Patagial att & -0.17 & 0.07 & -2.59 & $* *$ \\
\hline Captive group & 0.02 & 0.06 & 0.36 & NS \\
\hline Patagial:captive & -0.09 & 0.09 & -1.05 & NS \\
\hline Smooth terms & Edf & Ref. df & $F$ & $p$ \\
\hline Tracking duration & 5.60 & 5.60 & 7.20 & $* * *$ \\
\hline N. LoC & 6.30 & 6.30 & 85.68 & $* * *$ \\
\hline Date & 4.50 & 8.00 & 3.06 & $* * *$ \\
\hline Random effects & & Intercept Std. Dev & & N. Groups \\
\hline Individuals & & 0.10 & & 27 \\
\hline N. Observations & & 2848 & & \\
\hline Adjusted $R$ & & 0.26 & & \\
\hline
\end{tabular}

Number of days since deployment, number of locations and day of the year were included as smooth terms. The model was fitted with the restricted maximum likelihood using the gaussian family

NS $p \geq 0.05 ;{ }^{*} p<0.05 ;{ }^{* *} p<0.01 ;{ }^{* * *} p<0.001$

birds) or a leg band (7g, Fig. 4b; 13 birds). Patagial tags were placed on both wings within the patagium region $[23,34]$, while the leg band was fitted only around one leg. Age classes by tag type and group are presented in Additional file 1: Table S1. One individual was released twice, wherefore there are 28 tracking events of 27 individuals included in the study. This captive bred bird was first released on March 5, 2018 and equipped with GPS and patagial tag. On September 21, 2018 the same bird was found grounded and showed no interest in flying. Its patagial tag was removed and the bird was rehabilitated. On December 27, 2018 the bird was equipped with the same GPS model and leg band and released back into the wild. This allowed us to evaluate the effect of the tag replacement on the bird's flight performance. 
For tracking, we used second and third-generation GPS-GSM Wildlife Telemetry System from Cellular Tracking Technologies (1000-BT3 and 1000a series) with a weight of $68 \mathrm{~g}(90.1 \times 45.5 \times 22.1 \mathrm{~mm}$; Fig. 4c). The devices sampled positions $24 \mathrm{~h}$ /day at the median of either 1, 5 or $15 \mathrm{~min}$. Sampling frequency for some individuals was reduced at night, with $90 \%$ of locations across all individuals being collected between 4:00 and 16:00. The accuracy of the GPS devices was given at $2.5 \mathrm{~m}$ (50\% CEP statistical test) or $5 \mathrm{~m}$ (95\% 2dRMS statistical test).

Captive birds were born and raised in captivity at VulPro's rehabilitation centre and released before the age of one. All wild birds were found grounded due to minor injuries (e.g. heat stroke, starvation, weather) and admitted to the rehabilitation centre at VulPro for a couple of months before being released back into the wild. Before 2018, birds were released from the VulPro rehabilitation centre (long 27.953784, lat - 25.710670; captive-bred $=2$, wild $=6$ ) whereas after 2018 , from the release site located at Nooitgedacht (long 27.535714, lat - 25.855547; captive-bred $=11$, wild $=8$ ). At both these sites there are established vulture restaurants; however, Kane et al. [35] found that supplementary feeding sites do not alter the natural foraging behaviours of the Cape Vulture. Furthermore, the two release sites were $60 \mathrm{~km}$ apart along with the Magaliesburg mountain range, resulting in birds experiencing the same factors on release, such as the spatial topography, urbanisation, artificial feeding sites, etc. Therefore, we assume that artificial feeding sites had the same impact on each individual involved in the study.

\section{Data processing}

The initial data set included a total of 625,861 GPS locations from 27 individuals and 28 tagging events. We manually removed GPS locations falling outside the African continent. We then removed additional outliers based on speed between consecutive locations using the $R$ package ctmm to account for location error [36]: we set a conservative GPS error (user equivalent range error) of $10 \mathrm{~m}$, used the functions available in the ctmm package to compute speed and variance in speed at each location, and repeatedly removed locations with speed $>25 \mathrm{~ms}^{-1}$ [37]. This procedure was only used to detect and remove outliers but not for statistical purposes. The map in Fig. 1 shows the distribution of the clean trajectories.

After removing outliers we thinned the trajectories, in order to minimise potential biases in speed and distance calculations due to variable sampling frequency. Thinning was done by selecting from the original track only segments with $15 \pm 5$ min time lag. We then calculated time lag, horizontal displacement (straight-line displacement) and ground speed between locations of the selected segments. Ground speed was calculated as the straight-line displacement between two consecutive locations divided by the time lag. Both thinning and variable calculations were performed using the $\mathrm{R}$ package move [38].

For the next part of the analysis, we excluded segments with variance in speed $>0.5 \mathrm{~ms}^{-1}$ and time lag $>1 \mathrm{~h}$ because we considered them less reliable in the speed calculation. We classified the remaining segments into flying and not-flying based on a speed threshold of $2 \mathrm{~ms}^{-1}$ which we used to calculate metrics of flight performance to evaluate the effects of tag attachment. Specifically, for each individual and day of tracking we calculated: (i) Occurrence of flight (1 if at least one flight segment was recorded in the day, 0 otherwise); (ii) Proportion of time spent flying in a day (sum of flight time divided by tracking time for each day); (iii) Cumulative distance travelled (sum of horizontal displacements during flight segments, in $\mathrm{km}$ ); and (iv) Median ground speed (median of the speeds achieved during flight segments, in $\mathrm{ms}^{-1}$ ).

\section{Data analysis}

We used four GAMMs ( $\mathrm{R}$ package mgcv [39]) to test the effect of tag attachment on each of the above flight parameters. In all four models, attachment type and group (captive or wild) and their interaction term were included as fixed terms. The number of locations and number of days since release (deployment date) were also included in the models to account for the uneven tracking effort (number of locations and tracking duration) between days and individuals. These two parameters were included in the model as smooth terms (thin plate regression splines). Given the year-round tracking, we additionally included in the model Julian date (day of the year in the range 1-366) as cyclic cubic regression spline, to account for non-linear effects of seasonality. Finally, individual identity was included as a random effect in all models. Models including the proportion of time spent flying and occurrence of flight as response variables were fitted as logistic regressions with a "logit" link function. The variables cumulative distance travelled and median ground speed were square-root transformed and the corresponding models fitted using a Gaussian error distribution. Data processing and analysis were performed in $\mathrm{R}$ [40]. The complete $\mathrm{R}$ scripts to reproduce the analysis can be found in Additional file 2 .

\section{Supplementary Information}

The online version contains supplementary material available at https://doi. org/10.1186/s40317-021-00234-2. 
Additional file 1. File containing supplementary table and figures.

Additional file 2. File containing the complete $\mathrm{R}$ code to reproduce the data processing and analysis.

\section{Abbreviations}

Edf: Effective degrees of freedom; Ref. df: Reference degrees of freedom; Std. Dev: Standard deviation; N.: Number; NS: Not significant.

\section{Acknowledgements}

We would like to thank Alexandra Howard for her contribution in data preparation and the landowners, farmers and volunteers who have assisted us with vulture re-sightings, vulture collections and rehabilitation needs. We would also like to thank two anonymous reviewers for the valuable comments they provided during the revision process.

\section{Authors' contributions}

KW designed the study and provided the data. TC, MS and KS analysed and interpreted the data and wrote the first draft of the manuscript. KW, RK, WF and MW provided valuable comments on the manuscript. All authors read and approved the final version of the manuscript.

\section{Funding}

Open Access funding enabled and organized by Projekt DEAL.. VulPro would like to thank the following for financial support in making this project and paper possible; Cellular Tracking Technologies, Cheyenne Mountain Zoo, Colchester Zoo, Dallas Zoo, DHL Supply Chain, Hans Hoheisen Charitable Trust, International Association of Avian Trainers and Educators, Max Planck Institute of Animal Behavior, Natural Encounters Conservation Fund Inc. and the Tusk Trust. We acknowledge funding from the Max Planck Institute of Animal Behavior. TC was supported by the Slovene Human Resources Development and Scholarship Fund. MS was supported by the German Academic Exchange Service (DAAD). Both TC and MS were supported by the International Max Planck Research School for Organismal Biology.

\section{Availability of data and materials}

The data that support the findings of this study are available from Kerri Wolter (VulPro) but restrictions apply to the availability of these data, which were used under license for the current study, and so are not publicly available. Data are however available from the authors upon reasonable request and with permission of Kerri Wolter. R scripts used to analyse the data are published together with this article and can be found in Additional file 2.

\section{Ethics approval and consent to participate}

Work with Cape Vultures in this study was performed in accordance with ethical legislation (permits in Gauteng: 0-002619, North West Province: 10846 and 5723, and Limpopo: 06758 and 13677).

\section{Consent for publication}

Not applicable.

\section{Competing interests}

The authors declare that they have no competing interests.

\section{Author details}

${ }^{1}$ Department of Migration, Max Planck Institute of Animal Behavior, Am Obstberg 1, 78315 Radolfzell, Germany. ${ }^{2}$ Department of Biology, University of Konstanz, Universitätsstrae 10, 78464 Konstanz, Germany. ${ }^{3}$ Centre for the Advanced Study of Collective Behaviour, University of Konstanz, Universitätsstrae 10, 78464 Konstanz, Germany. ${ }^{4}$ VuIPro, Vulture Programme, Rietfontain, South Africa.

Received: 3 September 2020 Accepted: 9 February 2021 Published online: 09 March 2021

\section{References}

1. Powell LA, Lang JD, Krementz DG, Conroy MJ. Effects of radio transmitters on migrating Wood Thrushes. J Field Ornithol. 1998;69(2):306-15.
2. Kays R, Crofoot MC, Jetz W, Wikelski M. Terrestrial animal tracking as an eye on life and planet. Science. 2015. https://doi.org/10.1126/scien ce.aaa2478.

3. Williams HJ, Taylor LA, Benhamou S, Bijleveld Al, Clay TA, Grissac S, Demšar U, English HM, Franconi N, GómezLaich A, Griffiths RC, Kay WP, Morales JM, Potts JR, Rogerson KF, Rutz C, Spelt A, Trevail AM, Wilson RP, Börger L. Optimizing the use of biologgers for movement ecology research. J Anim Ecol. 2020;89(1):186-206. https://doi.org/10.1111/1365-2656.13094.

4. Barron DG, Brawn JD, Weatherhead PJ. Meta-analysis of transmitter effects on avian behaviour and ecology. Methods Ecol Evolut. 2010;1(2):180-7. https://doi.org/10.1111/j.2041-210x.2010.00013.x.

5. Bowlin MS, Henningsson P, Muijres FT, Vleugels RHE, Liechti F, Hedenström A. The effects of geolocator drag and weight on the flight ranges of small migrants. Methods Ecol Evolut. 2010;1(4):398-402. https://doi. org/10.1111/j.2041-210x.2010.00043.x.

6. Bodey TW, Cleasby IR, Bell F, Parr N, Schultz A, Votier SC, Bearhop S. A phylogenetically controlled meta-analysis of biologging device effects on birds: Deleterious effects and a call for more standardized reporting of study data. Methods Ecol Evolut. 2018;9(4):946-55. https://doi. org/10.1111/2041-210X.12934.

7. Stutchbury BJM, Tarof SA, Done T, Gow E, Kramer PM, Tautin J, Fox JW, Afanasyev $\mathrm{V}$. Tracking long-distance songbird migration by using geolocators. Science. 2009;323(5916):896. https://doi.org/10.1126/science.11666 64.

8. Gessaman JA, Nagy KA. Transmitter loads affect the flight speed and metabolism of Homing Pigeons. The Condor. 1988;90(3):662. https://doi. org/10.2307/1368356.

9. Bannasch R, Wilson RP, Culic B. Hydrodynamic apects of design and attachment of a back-mounted device in penguins. J Exper Biol. 1994;194(1):83-96.

10. Wanless S, Harris MP, Morris JA. Behavior of Alcids with Tail-Mounted radio transmitters. Colonial Waterbirds. 1989;12(2):158-63. https://doi. org/10.2307/1521336.

11. Kenward, RE. A manual for wildlife radio tagging, 2nd edition. Animal Conservation 2002;5(3):259-260. https://doi.org/10.1017/\$136794300 2212317

12. Portugal SJ, White CR. Miniaturization of biologgers is not alleviating the 5\% rule. Methods Ecol Evolut. 2018:9(7):1662-6.

13. Vandenabeele SP, Shepard EL, Grogan A, Wilson RP. When three per cent may not be three per cent; device-equipped seabirds experience variable flight constraints. Marine Biol. 2012;159(1):1-14. https://doi.org/10.1007/ s00227-011-1784-6.

14. Pennycuick C, Fast PL, Ballerstädt N, Rattenborg N. The effect of an external transmitter on the drag coefficient of a birds body, and hence on migration range, and energy reserves after migration. J Ornithol. 2012;153(3):633-44

15. Kay WP, Naumann DS, Bowen HJ, Withers SJ, Evans BJ, Wilson RP, Stringell TB, Bull JC, Hopkins PW, Börger L. Minimizing the impact of biologging devices: using computational fluid dynamics for optimizing tag design and positioning. Methods Ecol Evolut. 2019;10(8):1222-33.

16. Vandenabeele SP, Wilson RP, Wikelski M. New tracking philosophy for birds. Front Ecol Environ. 2013;11(1):10-2.

17. Vandenabeele SP, Grundy E, Friswell MI, Grogan A, Votier SC, Wilson RP. Excess baggage for birds: inappropriate placement of tags on gannets changes flight patterns. PLoS ONE. 2014;9(3):92657. https://doi. org/10.1371/journal.pone.0092657.

18. Brua RB. Negative effects of patagial tags on Ruddy Ducks. J Field Ornithol. 1998;69(4):530-5.

19. Zuberogoitia I, Arroyo B, O’Donoghue B, Zabala J, Martínez J.A, Martínez JE, Murphy S.G. Standing out from the crowd: are patagial wing tags a potential predator attraction for harriers (Circus spp.)? J Ornithol. 2012;153(3):985-9. https://doi.org/10.1007/s10336-012-0842-2.

20. Trefry SA, Diamond AW, Jesson LK. Wing marker woes: a case study and meta-analysis of the impacts of wing and patagial tags. J Ornithol. 2013;154(1):1-11. https://doi.org/10.1007/s10336-012-0862-y.

21. Botha A. A review of colour-marking techniques used on vultures in southern Africa. Vulture News. 2007;56:52-63.

22. Reading RP, Maude G, Hancock P, Kenny D, Garbett R. Comparing different types of patagial tags for use on vultures. Vulture News. 2015;67(2):33. https://doi.org/10.4314/vulnew.v67i2.3. 
23. Hirschauer MT, Wolter K, Forbes NA. A review of vulture wing anatomy and safe propatagial tag application methods, with case studies of injured vultures. JWildlife Rehabilitat. 2019;39(3):7-13.

24. Krüger S, Reid T, Amar A. Differential range use between age classes of Southern African bearded vultures Gypaetus barbatus. PLoS ONE. 2014;9(12):114920. https://doi.org/10.1371/journal.pone.0114920.

25. Reading RP, Azua J, Garrett T, Kenny D, Lee H, Paek WK, Reece N, Tsolmonjav P, Willis MJ, Wingard G. Differential movement of adult and juvenile Cinereous Vultures (Aegypius monachus) in Northeast Asia. J Asia-Pacific Biodiver. 2020;13(2):156-61. https://doi.org/10.1016/j.japb.2020.01.004.

26. Ruxton GD, Houston DC. Obligate vertebrate scavengers must be large soaring fliers. J Theoreti Biol. 2004;228(3):431-6. https://doi.org/10.1016/j. jtbi.2004.02.005

27. Buechley E.R, Şekercioğlu H. The avian scavenger crisis: looming extinctions, trophic cascades, and loss of critical ecosystem functions. Biol Conservat. 2016;198:220-8.

28. Taylor SS, Leonard ML, Boness DJ, Majluf P. Foraging trip duration increases for Humboldt Penguins tagged with recording devices. J Avian Biol. 2001;32(4):369-72. https://doi.org/10.1111/j.0908-8857.2001.32041 3.x.

29. Navarro J, González-Solís J, Viscor G, Chastel O. Ecophysiological response to an experimental increase of wing loading in a pelagic seabird. J Exper Marine Biol Ecol. 2008;358(1):14-9. https://doi.org/10.1016/j.jembe 2008.01.005.

30. Wilson R.P, Wilson M.-p.T.J. Tape: a Package-Attachment Technique for Penguins. Wildlife Soc Bull. 1989;17(1):77-9. https://doi. org/10.2307/3782045

31. Pennycuick CJ. Modelling the flying bird. Amsterdam: Elsevier; 2008.

32. Ogada D, Shaw P, Beyers RL, Buij R, Murn C, Thiollay JM, Beale CM, Holdo RM, Pomeroy D, Baker N, Krüger SC, Botha A, Virani MZ, Monadjem A,
Sinclair ARE. Another continental vulture crisis: Africa's vultures collapsing toward Extinction. Conservat Lett. 2016;9(2):89-97. https://doi. org/10.1111/conl.12182.

33. Calvo B, Furness RW. A review of the use and the effects of marks and devices on birds. Ring Migrat. 1992;13(3):129-58. https://doi. org/10.1080/03078698.1992.9674036.

34. Wolter K, Neser W, Hirschauer MT. Protocols for mass capturing, handling, and fitting tracking devices and patagial (wing) tags on vultures - version 3.0 (2018). https://vulpro.com/wp-content/ uploads/2020/02/Wolte r-et-al-Protocols-for-Mass-Capture-Handling- and-Fitting-tracking-devic es-on-Gyps-vultures-V3.0-Nov-20181.pdf

35. Kane A, Wolter K, Neser W, Kotze A, Naidoo V, Monadjem A. Home range and habitat selection of cape vultures gyps coprotheres in relation to supplementary feeding. Bird Study. 2016;63(3):387-94.

36. Fleming $\mathrm{CH}$, Calabrese JM. ctmm: continuous-Time movement modeling 2019.https://cran.r-project.org/package $=$ ctmm

37. Bruderer B, Boldt A. Flight characteristics of birds: I. radar measurements of speeds. Ibis. 2001;143(2):178-204.

38. Kranstauber B, Smolla M, Scharf AK. move: visualizing and analyzing animal track data. 2017. https://cran.r-project.org/package=move

39. Wood SN. Thin plate regression splines. J Royal Statist Soc Seri B: Statist Method. 2003;65(1):95-114. https://doi.org/10.1111/1467-9868.00374.

40. R Core Team: R: A Language and Environment for Statistical Computing, Vienna, Austria. 2019. https://www.r-project.org/

\section{Publisher's note}

Springer Nature remains neutral with regard to jurisdictional claims in published maps and institutional affiliations.
Ready to submit your research? Choose BMC and benefit from:

- fast, convenient online submission

- thorough peer review by experienced researchers in your field

- rapid publication on acceptance

- support for research data, including large and complex data types

- gold Open Access which fosters wider collaboration and increased citations

- maximum visibility for your research: over 100M website views per year

At BMC, research is always in progress.

Learn more biomedcentral.com/submissions 